\title{
Çocuk acil servisine getirilen 624 yenidoğanın geriye dönük olarak değerlendirilmesi
}

\author{
Gülçin Bozlu1, Mümün Fatih Sağcan', Yalçın Çelik², Necdet Kuyucu \\ ${ }_{1}^{1}$ Mersin Üniversitesi Tıp Fakültesi, Çocuk Sağlığı ve Hastalıkları Anabilim Dalı \\ ${ }^{2}$ Mersin Üniversitesi Tıp Fakültesi, Yenidoğan Bilim Dalı \\ ${ }^{3}$ Mersin Üniversitesi Tıp Fakültesi, Çocuk Enfeksiyon Hastalıkları Bilim Dalı
}

\section{Öz}

Amaç: Yenidoğan dönemi çocuk sağlığı açısından savunmasız bir dönemdir. Yirmi sekiz günlük ve öncesini kapsayan çok sayıda olgu çocuk acil servislere getirilmektedir. Bu çalışmada çocuk acil servisine getirilen yenidoğanların klinik ve demografik özellikleri değerlendirilmiștir. Yöntemler: Ocak 2017 ve Aralık 2017 arasında çocuk acil servisimize getirilen 28 günlükten küçük olan bebeklerin dosya kayıtları geriye dönük olarak incelendi. Hastaların yaş, cinsiyet, doğum haftası, doğum ağırlığı, doğumun gerçekleștiği yer, hastaneye getiriliş şekli, geliş şikayetleri ve hastaneye yatırılma nedenleri kaydedildi. Tanımlayıcı istatistik yöntemler kullanıldı. Bulgular: Bir yıl içerisinde çocuk acil servise gelen hasta sayısı 62448 olup, bunların 624 'ü (\%0.9) yenidoğan dönemindeydi. Yenidoğanların \%58.8'i erkekti ve \%77.9'u ilk bir hafta içerisinde doğmuştu. En sık başvuru şikayetleri sarılık (\%26.0), solunum sıkıntısı (\%25.2), prematürite (\%16.3) ve asfiksi (\%10.3) olarak bulundu. Bunların 489'u (\%78.4) yatırılarak tedavi edilmişti. Sonuç: Çocuk acil servisine yenidoğan dönemindeki başvurular ilk yedi gün en yüksek oranda olup en sık başvuru nedeni sarılık olarak saptanmıştır. Çocuk acil serviste görev yapan doktorların yenidoğanların sorunları ve özellikle yaşamın ilk haftasında gelişebilecek hastalıkları açısından bilgili olmaları yenidoğanların değerlendirilmesinde kolaylık sağlayabilir.

Anahtar kelimeler: Acil servis, yenidoğan dönemi, yenidoğan acili

\section{Retrospective evaluation of 624 neonates admitted to pediatric emergency department}

Objective: The neonatal period is a vulnerable period of pediatric health. There are a large number of pediatric emergency department visits in infants prior to 28 days old. In this study, we evaluated the characteristics of the neonates admitted to pediatric emergency department. Methods: In this retrospective study, we collected the data of neonates ( $\leq 28$ days of age) who were admitted to our pediatric emergency department between January 2017 and December 2017. Postnatal age, gender, gestational age, birth weight, place of birth, type of arrival to the hospital, reasons for admission and the indication of hospitalization were recorded. Descriptive statistics were used.

Yazının geliş tarihi:16.02.2018

Yazının kabul tarihi:19.03.2018

Sorumlu Yazar: Gülçin Bozlu, Mersin Üniversitesi Tıp Fakültesi, Çocuk Sağlığı ve Hastalıkları Anabilim Dall, Mersin

Tel: 032424100 00/2414, Eposta: gulnebi@hotmail.com 
Results: 624 of the 62448 children who visited the emergency department were newborn $(0.9 \%)$. Of those, $58.9 \%$ were male and the admission rate in neonates $\leq 7$ days of age was found to be $77.88 \%$. The most common presenting complaints were jaundice $(26.0 \%)$, difficulty breathing (25.2\%), prematurity (16.3\%) and asphyxi (10.3\%). 489 of the 624 infant were hospitalized (78.4\%). Conclusion: Pediatric Emergency Department admissions were at the highest rate for the first seven days and the most common cause was jaundice. Doctors working in the pediatric emergency department should be knowledgeable about the problems of the newborns and especially the diseases that can develop during the first week of life.

Keywords: Emergency department, neonatal period, newborn emergency

\section{Giriş}

Yenidoğan dönemi bebeğin anne karnı dışındaki yaşama adapte olmaya çalıștığı ve fizyolojik değişimlerin olduğu dönemdir. Hayatın ilk yılında gözlenen ölümlerin büyük bir bölümü bebeğin savunmasız olduğu bu dönemde

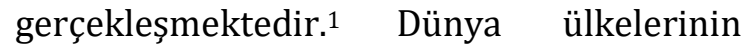
gelişmişlik düzeylerini belirlemede önemli ölçütlerden biri bebek ölüm oranıdır ve yenidoğan döneminde görülen hastalıklar toplum sağlığı açısından önem taşımaktadır. $\mathrm{Bu}$ dönemde hastalıkların seyri genellikle önceden öngörülemeyebilir ve sıklıkla da bebeğin hastaneye yatırılması gerekebilir. ${ }^{2}$

Yenidoğanlarda mortalite, genellikle aniden gelișen acil durumlara bağlıdır, erken tanı morbidite ve mortaliteyi önemli ölçüde

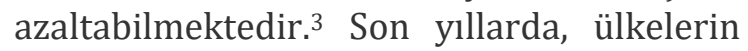
sosyal ve ekonomik politikaları nedeniyle birçok merkezde doğumdan kısa bir süre sonra anne ve bebeğin taburculuğu gündemdedir. Diğer ülkelerde olduğu gibi Türkiye'de de bu konu tartıșılmaktadır. ${ }^{4}$ Hastaneden erken taburcu edilen yenidoğanlar herhangi bir sorunla karşılaștıklarında, geniş bir hasta grubuna hizmet veren çocuk acil servislerine başvurmaktadır. Bu nedenle de, acil olsun veya olmasın yenidoğanla ilgili herhangi bir sorun yaşandığında acil servislere başvurunun arttığı düşünülmektedir. $\mathrm{Bu}$ çalışmada çocuk acil servisine getirilen yenidoğanların geriye dönük değerlendirilmesi yapılmış ve başvuru nedenleri incelenmiştir.

\section{Gereç ve Yöntemler}

Ocak 2017-Aralık 2017 tarihleri arasında çocuk acil servisimize getirilen yaşamının ilk 28 gününde olan 624 hastanın dosyaları geriye dönük olarak incelendi. Yenidoğanların yaş, cinsiyet, doğum haftası ve kilosu, doğum yeri, hastaneye geliş şekli, çocuk acile başvuru nedenleri ve hastaneye yatma endikasyonları değerlendirildi. Yenidoğanlar yaş gruplarına göre 0-7 gün, 814 gün, 15-21 gün ve 22-28 gün olmak üzere dört gruba ayrıldı. Dosya verileri tam olmayan hastalar çalışma dışı bırakıldı. Bir hastanın aynı tanıla tekrar tekrar acil servise girişleri tek kayıt olarak alındı. Dosya verileri geriye dönük taranarak yapılan bu çalışma için Mersin Üniversitesi Klinik Araştırmalar Etik Kurulu onayı alındı ve çalışma Helsinki Deklerasyonu Prensipleri'ne uygun olarak yapıldı. Hastaların verileri tanımlayıcı istatistik yapılarak değerlendirildi. Veriler ortalama \pm standart deviasyon (SD) olarak tanımlandı.

\section{Bulgular}

Cocuk acil servisimize bir yılda başvuran 62448 çocuğun 624'ünü (\%0.9) yenidoğanlar oluşturuyordu. Yenidoğanların \%58.8'i erkek ve \%77.9'u 0-7 günlüktü (Tablo 1). Ortalama doğum ağırlıkları $2659.7 \pm 905.8$ gram olup, gestasyonun $35.7 \pm 3.9$ haftasında doğmuşlardı. Bunların \%76.3'ü hastanemizde doğmuștu ve \%71.6'sı anneleri hastanemizden taburcu edilmeden çocuk acil servisimize getirilmişti (Tablo 1).

Annelerin yaş ortalaması $28.6 \pm 2.9$ olup \%67.6'si multipardı. Kayıtlarımıza göre; bu tarih aralığında hastanemizdeki canlı doğum sayısı 1024 olarak saptandı (765 sezaryen, 259 vajinal doğum). Hastanemizde doğan bebeklerin yenidoğan döneminde çocuk acil servisine başvurma oranı \%46.4 
olarak bulundu. Hastaların bașvuru nedenleri sıklık sırasına göre; sarılık (\%26.0), solunum sikıntısı (\%25.2), prematürite $(\% 16.3)$ ve asfiksi $(\% 10.3)$ idi (Tablo 2).

Başvuran yenidoğanların 489'u (\%78.4) yatırılarak tedavi edilmişti.
Yenidoğanların acile başvuru zamanları ay ve mevsimlere göre değerlendirildiğinde en sık başvuruların sonbahar (\%29.6) ve yaz (\%26.4) mevsimlerinde olduğu, başvuruların en sık olduğu ayların ise eylül (\%9.6) ve ekim (\%9.5) ayları olduğu saptandı (Şekil 1).

Tablo 1. Acil servise getirilen yenidoğanların özellikleri

Değişken $\quad$ Hasta sayısı (\%)

Cinsiyet

Erkek

$\mathrm{Kiz}$

Başvuru zamanı

0-7 gün

8-14 gün

15-21 gün

22-28 gün

Doğum yeri

Hastanemizde

Mersin'de başka bir sağlık kuruluşunda

Evde

Mersin dışında

Hastaneye geliş şekli

Hastanemizde anne taburcu olmadan getirilen

Kendi olanakları ile acil servisimize getirilen

112 servisi ile acil servisimize getirilen
$476(76.3)$

$5(0.8)$

$14(2.2)$

$447(71.6)$

$124(19.9)$

$367(58.8)$

$257(41.2)$

$486(77.9)$

$82(13.1)$

$34(5.5)$

$22(3.5)$

$129(20.7)$

$53(8.5)$ 
Tablo 2. Acil servise getirilen yenidoğanların tanıları

\begin{tabular}{ll}
\hline Tanı & Hasta sayısı (\%) \\
\hline Sarılık & $162(26.0)$ \\
Solunum sıkıntısı & $157(25.2)$ \\
Prematurite & $102(16.3)$ \\
Asfiksi & $64(10.3)$ \\
Metabolik nedenler/ hastalıklar & $28(4.5)$ \\
İntrauterin gelişme geriliği & $25(4.0)$ \\
Benign intestinal patolojiler & $22(3.5)$ \\
(kusma, ishal, kolik, beslenme bozuklukları) & \\
Enfeksiyonlar & $14(2.2)$ \\
Cerrahi nedenler & $11(1.8)$ \\
Nörolojik nedenler & $8(1.3)$ \\
Konjenital kalp hastalıkları & $7(1.1)$ \\
Renal hastalıklar & $7(1.1)$ \\
Dermatolojik nedenler & $7(1.1)$ \\
Oftalmolojik nedenler & $5(0.8)$ \\
Sendromik bebekler & $4(0.6)$ \\
\hline & $1(0.2)$ \\
\hline
\end{tabular}

\section{Tartışma}

Yașamın ilk 28 gününü kapsayan yenidoğan dönemi, çocuk sağlığı açısından en kritik dönemlerden biridir. Özellikle hastanede doğan bebeklerde doğum sonrası yapılan destek uygulamaları (göz için proflaksi, K vitamini ve hepatit B aşısı) ve emzirme, göbek bakımı, sarılık konularındaki eğitim sonraki dönemde yapılacak sağlık hizmetlerini etkileyebilir. Bu nedenle hastanede yapılan doğumlar sonrasında bebek ve annenin en kısa sürede ama emniyetli biçimde taburcu edilmesi önemlidir. Hastanede yatma süresinin kısa olması hastane kaynaklı enfeksiyonların riskini azaltma, bebek ve annenin ev ortamında daha uyumlu olmasını sağlama ve hastane maliyetini azaltma açısından avantaj sağlamaktadır. Sağlık ve ekonomik politikalar gereği olan uygulamalar birçok ülkede tartışma konusudur. Amerikan Pediatri Akademisi doğum sonrası taburcu edilme için uygun süreyi normal doğumlar için 48 saat ve sezaryen sonrası için 96 saat olarak önermektedir. ${ }^{5}$ 


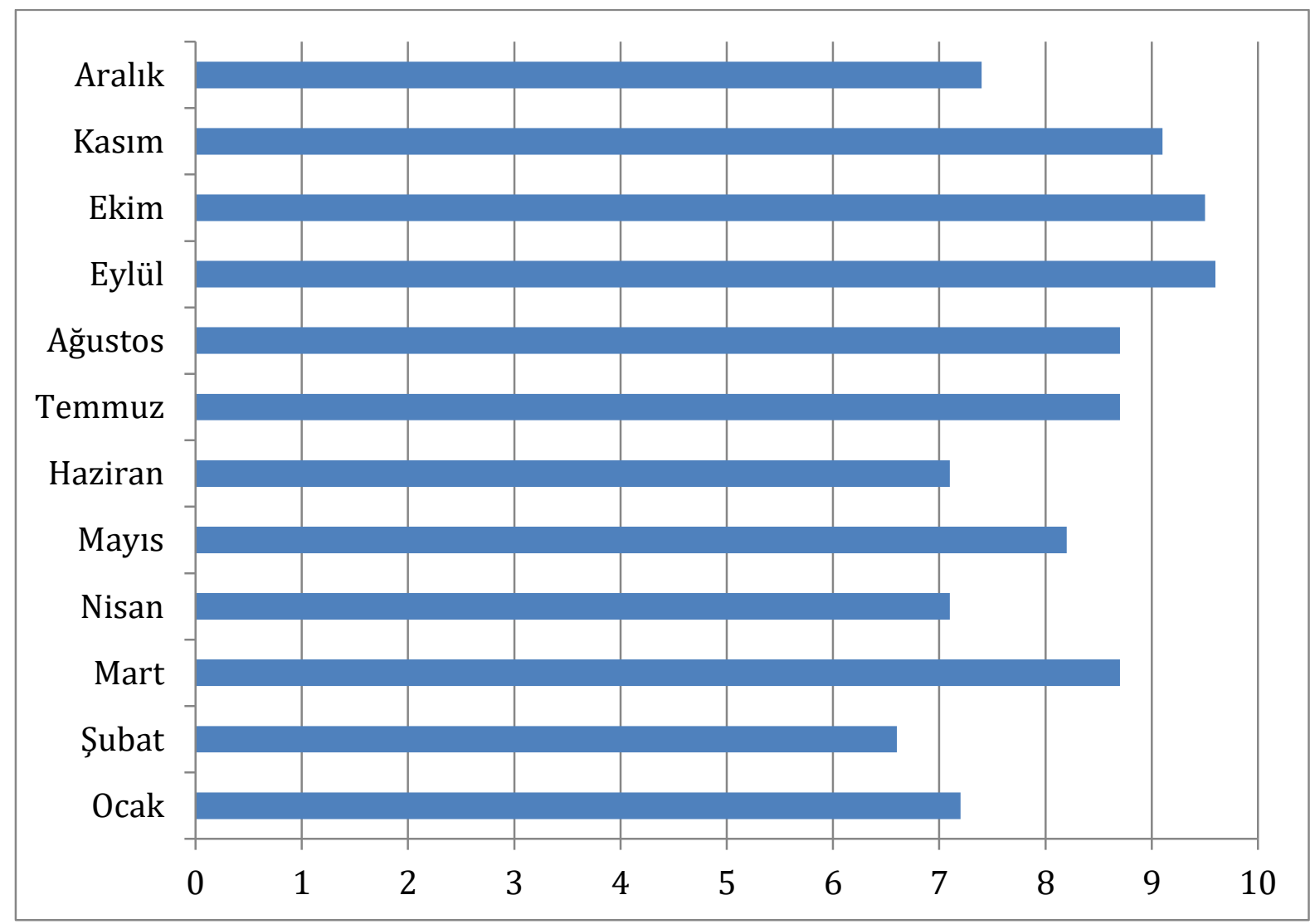

Şekil 1. Başvuruların aylara göre dağılımı (\%)

Doğum sonrası hastanede kalış sürelerinin azalmasıyla birlikte hastaneye tekrar başvuru oranlarının artıp artmadığıyla ilgili tartışmalı sonuçlar mevcuttur. ${ }^{2,6}$ Yenidoğan döneminde karşılaşılan sorunlarda ailelerin sıklıkla başvuruda bulunduğu yer hastanelerin çocuk acil servisleridir. ${ }^{7}$ Yapılan bir çalışmada, 2-10 günlük yenidoğanların çocuk acil servise getirilme oranlarının beş ylllk süreçte 4.3/10000'den 7.8/10000'e yükseldiği bildirilmiștir. ${ }^{2}$ Danielsen ve ark. ${ }^{8}$ iki yıllık süre içerisinde yenidoğanların hastaneden erken taburculuğundan kaynaklı olduğu düşünülen yeniden hastaneye başvurularında \%15'lik bir artış olduğunu, bu tutumun yenidoğan döneminde çocuk acil servise başvuru oranlarını 25.6/1000'den 30.2/1000'e çıkardığını bildirmiştir.

Ülkemizde çocuk acil servisine başvuran yenidoğanlarla ilgili sınırlı sayıda çalışma mevcuttur. Batu ve ark. ${ }^{4}$ yaptıkları prospektif çalışmada, yenidoğan döneminde acil servise başvuran 531 hastanın demografik, klinik özelliklerini ve bunların perinatal faktörlerle ilişkisini incelemiş, acil servise 6 aylık süre içerisinde başvuran yenidoğanların diğer çocuk hastalara oranının \%1.9 olduğunu, bunların \%57.3'sinin erkek ve \%52.0'ının 14 günlükten küçük olduğunu bildirmişlerdir. Çalışmamızda olguların çoğunun hastanemizde doğan ve doğum sonrasında anneleri henüz taburcu edilmeden önce acil servisimize getirilen yenidoğanlar olduğu, önemli bir kısmının doğumdan sonra ilk bir haftalık dönemdeki erkek bebeklerin olduğu saptanmıştır.

Yenidoğan döneminde acil servise başvuru sebeplerinin çoğunun benzer yakınmalardan kaynaklandığ bildirilmektedir. ${ }^{4}$ Çocuk acil servisine başvuran yenidoğanların \%20'sinden fazlasında sarılık yakınması yer almaktadır. 1,7,9 Batu ve ark.'nın ${ }^{4}$ çalışmasında çocuk acil servisine başvuran yenidoğanlarda en sik görülen sebeplerin sarılık (\%23.4), irritabilite (\%9.5) ve kusma (\%7.1) olduğu, hastaların \%23.2'sinin hastaneye yatırıldığı bildirilmiştir. Başka bir 
çalıșmada sarılık ve beslenme problemleri nedeniyle hastaların \%32.9'unun yatırılarak tedavi edildiği bildirilmiştir.7 Çalışmamızda en sık gözlenen başvuru nedeninin sarılık olduğu, bunu prematürite ve asfiksi tanılarının izlediği, başvuran yenidoğanların \%7.2'sinin hastanemizde doğmuş olduğu ve bunların da \%78.4'ünün yatırılarak tedavi gördüğü saptanmıştır. Çalışmalardaki farklı şikayetlerle olan farklı hastaneye yatırılma oranları, çalışmaların tasarımı ve çalışmaya dahil edilen hastaların farklılıklarından kaynaklanıyor olabilir.

Çalıșmamızın tek merkezli olması ve verilerin dosya taranarak geriye dönük elde edilmesi önemli kısıtlamalarındandır. Yenidoğan döneminde bebeğe ait faktörlerin yanı sıra anneye ait faktörler de çocuk acil servise başvuru oranlarını etkileyebilir. Çocuk acil servis dosyalarında annelere ait detaylı verilerin hepsi bulunmağı için, çalışmamızda anneye ait faktörlerin ne derecede etkili olduğu değerlendirilememiştir. Ayrıca çalışmamız bir yıllık dönemi kapsadığı için, yıllar içerisinde anne ve yenidoğanın erken taburculuğu eğiliminin çocuk acil servise başvuru oranlarını nasıl etkilediğini cevaplayamamaktadır. Ülkemizde çocuk acile başvuran yenidoğanlarla ilgili fazla çalıșma olmaması nedeniyle elde ettiğimiz geriye dönük dosya verilerinin incelenmiş olması ileride yapılacak prospektif ve geniş serili çalışmalara yön verebilir.

Sonuç olarak, çalışmamız yenidoğan döneminde olguların önemli bir kısmının ilk bir hafta içerisinde çocuk acil servislerine getirildiğini göstermektedir. $\mathrm{Bu}$ kritik dönemde geniş bir hasta grubuna hizmet veren çocuk acil servislerine başvuran hastalar; riskli grup olarak değerlendirilmeli, tüm yakınmalar ve bulgular ciddiye alınmalı, yenidoğan servislerinde hizmet verenlerin yanı sıra acil serviste görevli hekim ve sağlık personelinin de yenidoğan hastalarla ilgili farkındalığı ve bilgisi olmalıdır. Uygun taburculuk zamanın ne olduğunu ve bu sürenin acil servise başvuruları nasıl etkilediğini değerlendiren büyük hasta sayıları ile yapılacak prospektif çalışmalara ihtiyaç vardır.

\section{Kaynaklar}

1. Lee HC, Bardach NS, Maselli JH, Gonzales R. Emergency department visits in the neonatal period in the United States. Pediatr Emerg Care 2014;30(5):315-318.

2. Sacchetti AD, Gerardi M, Sawchuk P, Bihl I. Boomerang babies: emergency department utilization by early discharge neonates. Pediatr Emerg Care 1997;13(6):365-368.

3. Wang XL, Wang J, Yuan L, Shi WJ, Cao Y, Chen C. Trend and causes of neonatal mortality in a level III children's hospital in Shanghai: a 15-year retrospective study. World J Pediatr 2018;14(1):44-51.

4. Batu ED, Yeni S, Teksam 0. The factors affecting neonatal presentations to the pediatric emergency department. J Emerg Med 2015;48(5):542-547.

5. Oh W, Merenstein G. Fourth edition of the Guidelines for Perinatal Care: summary of changes. Pediatrics 1997;100(6):1021-2.

6. Liu LL, Clemens CJ, Shay DK, Davis RL, Novack AH. The safety of newborn early discharge. The Washington State experience. JAMA 1997;278:293-298.

7. Millar KR, Gloor JE, Wellington N, Joubert GI. Early neonatal presentations to the pediatric emergency department. Pediatr Emerg Care 2000;16(3):145-150.

8. Danielsen B, Castles AG, Damberg CL, Gould JB. Newborn discharge timing and readmissions: California, 1992-1995. Pediatrics 2000;106(1 Pt 1):31-39.

9. Flanagan CF1, Stewart M. Factors associated with early neonatal attendance to a paediatric emergency department. Arch Dis Child 2014;99(3):239-243. 